Dedicated to Prof. Qamrul Hasan Ansari on the occasion of his $60^{\text {th }}$ anniversary

\title{
Intersection theorems with applications in set-valued equilibrium problems and minimax theory
}

\section{Mircea Balaj}

\begin{abstract}
.
In this paper, we obtain three intersection theorems that can be considered versions of Theorem 3.1 from the paper [Agarwal, R. P., Balaj, M. and O'Regan, D., Intersection theorems with applications in optimization, J. Optim. Theory Appl., 179 (2018), 761-777]. As will be seen, there are two major differences between the hypotheses of the above mentioned theorem and those of our results. Applications of the main results are considered in the last two sections of the paper.
\end{abstract}

\section{REFERENCES}

[1] Agarwal, R. P., Balaj, M. and O'Regan, D., Intersection theorems with applications in optimization, J. Optim. Theory Appl., 179 (2018), 761-777

[2] Agarwal, R. P., Balaj, M. and O'Regan, D., Common fixed point theorems in topological vector spaces via intersection theorems, J. Optim. Theory Appl., 173 (2017), 443-458

[3] Agarwal, R. P., Balaj, M. and O'Regan, D., An intersection theorem for set-valued mappings, Appl. Math., 58 (2013), 269-278

[4] Aliprantis, C. D., Border, K. C., Infinite Dimensional Analysis. A hitchhiker's guide, Springer, Berlin, 2006

[5] Ansari, Q. H., Konnov, I. V. and Yao, J. C., On generalized vector equilibrium problems, Nonlinear Anal., 47 (2001), 543-554

[6] Ansari, Q. H., Farajzadeh, A. P. and Schaible, S., Existence of solutions of strong vector equilibrium problems, Taiwanese J. Math., 16 (2012), 165-178

[7] Balaj, M., Weakly G-KKM mappings, G-KKM property, and minimax inequalities, J. Math. Anal. Appl., 294 (2004), 237-245

[8] Balaj, M., Three types of variational relation problems, Taiwanese J. Math., 17 (2013), 47-61

[9] Balaj, M., Luc, D. T., On mixed variational relation problems, Comput. Math. Appl., 60 (2010), 2712-2722

[10] Borwein, J., Multivalued convexity and optimization: a unified approach to inequality and equality constraints, Math. Programming, 13 (1977), 183-199

[11] Chiang, Y., Chadli, O. and Yao, J. C., Generalized vector equilibrium problems with trifunctions, J. Global Optim., 30 (2004), 135-154

[12] Fan, K., A generalization of Tychonoff's fixed point theorem, Math. Ann., 142 (1961), 305-310

[13] Fu, J. Y. and Wan, A. H., Generalized vector equilibrium problems with set-valued mappings, Math. Methods Oper. Res., 56 (2002), 259-268

[14] Hou, S. H., Yu, H. and Chen, G. Y., On vector quasi-equilibrium problems with set-valued maps, J. Optim. Theory Appl., 119 (2003), 485-498

[15] Junlouchai, P. and Plubtieng, S., Existence of solutions for generalized variational inequality problems in Banach spaces, Nonlinear Anal., 74 (2011), 999-1004

[16] Kien, B. T., Wong, N. C. and Yao, J. C., Generalized vector variational inequalities with star-pseudomonotone and discontinuous operators, Nonlinear Anal., 68 (2008), 2859-2871

Received: 08.05.2019; In revised form: 07.08.2019; Accepted: 14.08.2019

2010 Mathematics Subject Classification. 49J53, 49J40.

Key words and phrases. intersection theorem, variational relation problem, set-valued equilibrium problem, minimax inequality. 
[17] Kim, W. K., A fixed point theorem in a Hausdorff topological vector space, Comment. Math. Univ. Carolin., 36 (1995), 33-38

[18] Konnov, I. V. and Yao, J. C., On the generalized vector variational inequality problem, J. Math. Anal. Appl., 206 (1997), 42-58

[19] Lin, L. J. and Chen, H. L., The study of KKM theorems with applications to vector equilibrium problems with implicit vector variational inequalities problems, J. Global Optim., 32 (2005), 135-157

[20] Li, X. B. and Li, S. J., Existence of solutions for generalized vector quasi-equilibrium problems, Optim. Lett., 4 (2010), 17-28

[21] Luc, D. T., An abstract problem in variational analysis, J. Optim. Theory Appl., 138 (2008), 65-76

[22] Luc, D. T., Theory of Vector Optimization, Lecture Notes in Economics and Mathematical Systems, 319. Springer-Verlag, Berlin, 1989

[23] Park, S., Some coincidence theorems on acyclic multifunctions and applications to KKM theory, in Fixed point theory and applications, World Sci. Publ., River Edge, NJ. 1992, 248-277

[24] Sion, M., On general minimax theorems, Pacific J. Math., 8 (1958), 171-176

[25] Yu, J. and Yang, H., Existence of solutions for generalized variational inequality problems, Nonlinear Anal., 71 (2009), 2327-2330

\author{
UNIVERSITY OF ORADEA \\ DEPARTMENT OF MATHEMATICS \\ ROMANIA \\ E-mail address: mbal a jeuoradea .ro
}

